\title{
Exploration of isoxanthohumol bioconversion from spent hops into 8-prenylnaringenin using resting cells of Eubacterium limosum
}

\author{
Esther Moens ${ }^{1,2}{ }^{(0}$, Selin Bolca', Tom Van de Wiele ${ }^{2}$, Anita Van Landschoot ${ }^{3}$, Jan L. Goeman ${ }^{4}$, Sam Possemiers ${ }^{1}$ \\ and Willy Verstraete $5^{*}$
}

\begin{abstract}
Hops is an almost unique source of the potent phytoestrogen 8-prenylnaringenin (8-PN). As hops contain only low levels of 8-PN, synthesis may be more attractive than extraction. A strain of the Gram-positive Eubacterium limosum was isolated previously for 8-PN production from more abundant precursor isoxanthohumol (IX) from hops. In this study, spent hops, an industrial side stream from the beer industry, was identified as interesting source of IX. Yet, hopderived compounds are well-known antibacterial agents and the traces of a large variety of different compounds in spent hops interfered with growth and IX conversion. Critical factors to finally enable bacterial 8-PN production from spent hops, using a food and feed grade medium, were evaluated in this research. The use of bacterial resting cells and complex medium at a pH of 7.8-8 best fulfilled the requirements for 8-PN production and generated a solid basis for development of an economic process.
\end{abstract}

Keywords: Eubacterium limosum, Hop fermentation, Antibacterial, Isoxanthohumol, 8-prenyInaringenin, Industrial fermentation

\section{Introduction}

The prenylated flavanone 8-prenylnaringenin (8-PN) is known as a very potent phytoestrogen (Milligan et al. 1999; Schick and Schwack 2018) and is almost exclusively found in hops. Yet, concentrations of 8-PN are only $0.025-0.060 \mathrm{~g} \mathrm{~kg}^{-1}$ in hop strobili (often called hop cones) (Rong et al. 2000). This fact hampers commercially viable recovery of 8-PN through extraction and makes (bio-) synthesis more attractive to obtain the compound at large quantities. Xanthohumol $(\mathrm{X})$ is a primary chalcone in hops, present at $0.1-1 \%$ on dry weight in the lupulin glands (Stevens et al. 1999a). Isoxanthohumol (IX) is readily formed from X by acid-catalyzed

*Correspondence: Willy.Verstraete@avecom.be

${ }^{5}$ AVECOM NV, Ind Weg 122P, 9032 Wondelgem, Belgium

Full list of author information is available at the end of the article cyclization in the acidic conditions of the upper gastrointestinal tract (Nikolic et al. 2005), by chemical isomerization in alkaline conditions (Stevens et al. 1999b; Wilhelm and Wessjohann 2006; Kamiński et al. 2017), or by enzymatic cyclization using microbial transformations (Kim et al. 2019). Spectroscopic analysis confirmed that IX as such produced was a racemic mixture of (2S-) and (2R-) IX (Kim et al. 2019) and also in hop or hop pellets, IX and 8-PN were present as a racemate (Moriya et al. 2018). In vivo, IX is further enzymatically converted to $8-\mathrm{PN}$ via hepatic P450 drug metabolizing enzymes and by gut bacteria (van Breemen et al. 2014). A strain of the anaerobic bacterium Eubacterium limosum (LMG P23546), a gut commensal in some individuals, has indeed been isolated before and used for efficient conversion of pure IX (>99\%) into 8-PN at up to $90 \%$ conversion efficacy (Possemiers et al. 2005). Martinez et al. (2015) studied
Springer Open (c) The Author(s) 2020. This article is licensed under a Creative Commons Attribution 4.0 International License, which permits use, sharing, adaptation, distribution and reproduction in any medium or format, as long as you give appropriate credit to the original author(s) and the source, provide a link to the Creative Commons licence, and indicate if changes were made. The images or other third party material in this article are included in the article's Creative Commons licence, unless indicated otherwise in a credit line to the material. If material is not included in the article's Creative Commons licence and your intended use is not permitted by statutory regulation or exceeds the permitted use, you will need to obtain permission directly from the copyright holder. To view a copy of this licence, visit http://creativeco mmons.org/licenses/by/4.0/. 
enantiospecific pharmacokinetics of IX in rat and monitored the appearance of 8-PN (Martinez and Davies 2015). Yet, as (S-) 8-PN was found excreted in the urine in greater amounts than (R-) 8-PN, further enantiospecific in vivo bioactivity studies are needed.

Spent hops, a side product generated by industrial extraction of bitter acids from hop cones for the beer brewing industry, was presumed to be an economically interesting source of $\mathrm{X}$ and its isomer IX. Supercritical $\mathrm{CO}_{2}\left(\mathrm{sCO}_{2}\right)$ is the most common solvent for extraction of bitter acids from hop cones and has very high selectivity for the latter compounds. An interesting 8-PN bioproduction process could thus consist of alkaline pretreatment of $\mathrm{X}$ in spent hops (spent hop-X), yielding the isomerized spent hop-IX, and subsequent bioconversion of the latter into 8-PN. Traces of particular compounds have been quantified in spent hops (Krishna et al. 1986; Anioł et al. 2007; Aniol and Zolnierczyk 2008; Rój et al. 2015), yet, while the amount of $X$ was almost not affected by $\mathrm{sCO}_{2}$ extraction, extensive characterization of the main other residuals in different batches of spent hops is not available. It is however clear that spent hops may still contain traces of a complex mixture of different compounds. Hop constituents, mainly the bitter acids, have next to their 'hoppy taste', a long-term use as preserving agent, minimizing bacterial spoilage. The molecules are highly active, requiring multiple bacterial resistance mechanisms to a heterogeneous mixture (Sakamoto and Konings 2003; Suzuki et al. 2006; Behr and Vogel 2009, 2010; Yin et al. 2018). Resistance includes both ionophore and oxidative stress induced mechanisms which made researchers in the early nineties conclude that any antimicrobial tested thus far could not simulate the stress induced by hop compounds in bacteria (Fernandez and Simpson 1993). To counteract the stress induced by the hop-derived ionophores, resistant cells, such as some beer spoilage lactic acid bacteria have used specific $A B C$ or proton motive force dependent transporters to remove hop compounds or intercellularly released protons from the ionophores into the external environment (Sakamoto et al. 2001; Suzuki et al. 2002) (Fig. 1a). Based on the general acceptance of hop antibacterial effects and the low minimum inhibitory concentrations (MIC) reported by some researchers (Cermak et al. 2017; Bartmańska et al. 2018; Bocquet et al. 2019), it was anticipated that spent hop extracts would strongly affect the metabolism of Eubacterium limosum.

Eubacterium limosum can use the Wood-Ljungdahl (WL) pathway for demethylation of phenolic compounds (Genthner et al. 1981; Drake 1994; Liu and Suflita 1994). This pathway was thus suggested as the most likely metabolism for IX conversion (Fig. 1b) (Drake 1994; Studenik et al. 2012; Jeong et al. 2015). For methylotrophic reactions in Eubacterium limosum, inducible enzymes and complex patterns of diauxic growth and (co-) metabolic regulations have been described (Pacaud et al. 1985, 1986; Lindley et al. 1987; Cocaign et al. 1991; Loubiere and Lindley 1991; Loubiere et al. 1992; Lebloas et al. 1994, 1996). Whereas during growth on sugars, the WL pathway can be used to maintain the redox balance but there is no need that the pathway is coupled to energy conservation (Fig. 1c), in absence of sugars, the pathway must be coupled to net ATP synthesis such as via ion gradient-driven phosphorylation by ATP synthases (Müller 2003).

In this research, different strategies, physical (biomass entrapment), chemical ( $\mathrm{sCO}_{2}$ and hexane (re-) extraction of (spent) hops), biotechnological (medium optimization, exploration of resting cell conversions) have been investigated in order to achieve fermentation of antibacterial industrial side stream spent hops. Major factors to optimize were solubility of IX, toxicity of spent hops residuals and induction of conversion enzymes (Fig. 1).

\section{Materials and methods \\ Hops and spent hops treatments}

Hop and spent hop pellets were obtained from hop manufacturing company Hopsteiner (Hopfen GmbH, Mainburg, Germany), Barth-Haas Group (Paddock Wood, Kent, United Kingdom) and from a local brewery (Van Steenberge, Ertvelde, Belgium). Spent hop pellets were isomerized under alkaline conditions and an IX rich precipitate was obtained by subsequent acid precipitation. In brief, $50 \mathrm{~g}$ of spent hops was suspended in $1 \mathrm{~mol} \mathrm{~L}^{-1}$ $\mathrm{KOH}$. The suspension was stirred at room temperature during 90 min while the $\mathrm{pH}$ was kept at $\mathrm{pH} 13-14$. Subsequently, the suspension was centrifuged $10 \mathrm{~min}$ at $3220 \mathrm{~g}$ (C5810, Eppendorf, Hamburg Germany). The $\mathrm{pH}$ of the supernatant was lowered to $\mathrm{pH} 5.6$ using $10 \mathrm{~mol} \mathrm{~L}^{-1} \mathrm{HCl}$, leaving the suspension to precipitate overnight. The suspension was again centrifuged (10 min at $3220 \mathrm{~g}$ ) and the pellet was washed three times using distilled water. Water from the pellet was removed with the use of a rotavapor (BÜCHI, Hendrik-Ido-Ambacht The Netherlands) and/ or the pellet was directly suspended in ethanol or methanol. Alternatively, the precipitate was stored at $-20{ }^{\circ} \mathrm{C}$ until further use. Stock solutions in ethanol or methanol, standardized at $5 \mathrm{~g} \mathrm{IX} \mathrm{L}^{-1}$ were stored in the freezer at $-20{ }^{\circ} \mathrm{C}$. IX used as positive control in the incubation studies was obtained via a dichloromethane/methanol $(95 / 5, \mathrm{v} / \mathrm{v})$ extraction of $35.6 \mathrm{~g}$ isomerized spent hop precipitate. The extract was purified with flash chromatography on silica gel $(60-200 \mu \mathrm{m}, \mathrm{ROCC}): 12.4 \mathrm{~g}$ extract was dissolved in a minimal amount of ethyl acetate and this solution was eluted on 1500 g Silica using dichloromethane/methanol (95/5) as eluent. The fractions that 


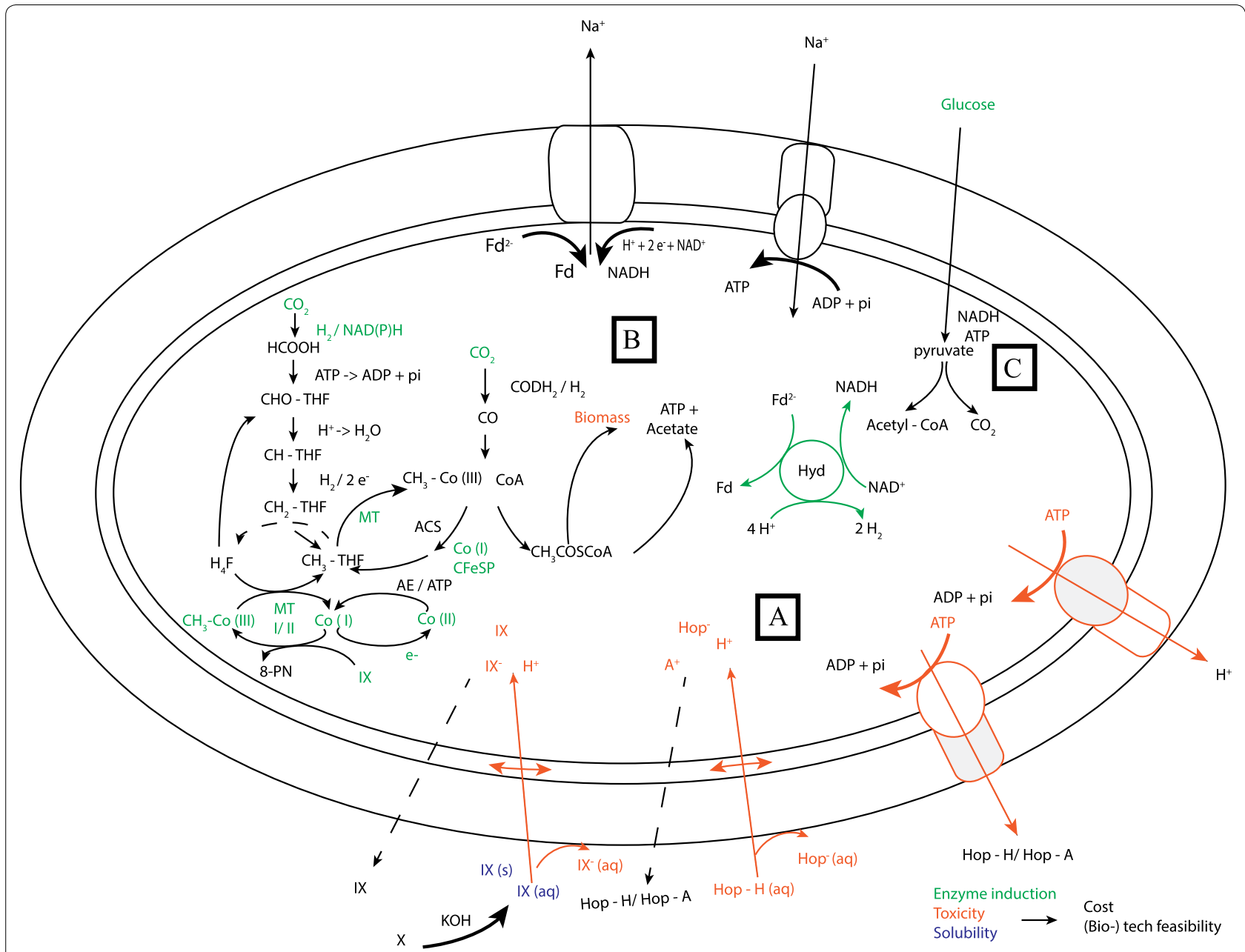

Fig. 1 Schematic representation of presumed factors influencing the conversion of abundant hop metabolite xanthohumol $(X)$ to 8-prenylnaringenin (8-PN). The process starts with conversion of X from spent hops into isoxanthohumol (IX) by chemical isomerization with $\mathrm{KOH}$, followed by enzymatic demethylation of IX into 8-PN by Eubacterium limosum. Cellular transport of hop compounds may occur via diffusion or via specific transporters (A). Conversion of IX to 8-PN is suggested to occur via the Wood-Ljungdahl pathway in absence (B) or presence (C) of carbohydrates such as glucose. The major enzymes involved in O-demethylation of IX are methyltransferase I (MT I), corrinoid protein (CFeSP) with cobalt in the respective oxidation states $\mathrm{Co}(\mathrm{x})$, methyltransferase II (MT II), activating enzyme (AE), Coenzyme A (CoA), carbon monoxide dehydrogenase (CODH), acetyl-CoA synthase (ACS). Small adaptations were made from the schemes provided by Drake (1994), Sakamoto (2003), Studenik (2012), Jeong (2015). The green, red and blue parts in the figure may be important factors in the study of solubility of IX, toxicity of spent hops residuals and induction of conversion enzymes

contained IX as checked by TLC (Machery-Nagel, SILG25 (UV254) $0.25 \mathrm{~mm}$ ) under $254 \mathrm{~nm}$ UV light were collected and evaporated in vacuo. This procedure was repeated three times, each time collecting the IX containing fractions. Finally, the obtained residue was triturated with diethyl ether and $800 \mathrm{mg}$ final product (IX) was obtained. The purity was checked by comparison of the peak area with reference materials using HPLC-DAD (Hitachi Chromaster, VWR, Leuven Belgium). The mass of IX was confirmed by LC-MS (Agilent 1100 HPLC coupled to an Agilent G1956D MS detector with ESI ionization source, Diegem Belgium). The 1H-NMR spectrum was recorded on Brüker Avance $400 \mathrm{MHz}$ NMR (Kontich Belgium) and found to be identical to that of the reference material (Possemiers 2007).

Hexane extraction of (spent) hops was done by batch extraction at room temperature based on the method described by Aniol and coworkers (Aniol and Zolnierczyk 2008). Supercritical $\mathrm{CO}_{2}\left(\mathrm{sCO}_{2}\right)$ extraction was performed on spent hops at lab scale as described by Van Opstaele and coworkers using Dionex SFE-703 supercritical fluid extractor (Dionex, Sunnyvale USA) (Van Opstaele et al. 2012). The $\mathrm{sCO}_{2}$ extraction was performed at the KAHO Sint-Lieven University College, Laboratory 
of Enzyme, Fermentation and Brewing Technology (Gent Belgium).

\section{Bacterial culture}

The 8-PN-producing strain Eubacterium limosum LMG P23546, isolated by Possemiers et al. 2007 was used in all experiments (Possemiers 2007). Experiments were initially performed in brain heart infusion (BHI) medium (Oxoid, Hampshire UK) with addition of $0.5 \mathrm{~g} \mathrm{~L}^{-1}$ cysteine $\mathrm{HCl}$ (Merck, Darmstadt Germany) at $37{ }^{\circ} \mathrm{C}$, using their methods. Bioconversion of pure IX (>99\%) into 8-PN by growing E. limosum in BHI medium at $25 \mathrm{~mL}$ scale was demonstrated by Possemiers and coworkers at a concentration of $25 \mathrm{mg} \mathrm{IX} \mathrm{L}^{-1}$ and was used as positive control in this study (Possemiers et al. 2005). A minimal medium was previously optimized in our lab for maximal biomass production, starting from the medium reported by Leclerc et al. (1997) for isolation of acetogens from human colon (Leclerc et al. 1997) (data not shown). The composition consisted of glucose, $20 \mathrm{~g} \mathrm{~L}^{-1}$; $\left(\mathrm{NH}_{4}\right)_{2} \mathrm{SO}_{4}, 1 \mathrm{~g} \mathrm{~L}^{-1}, \mathrm{NaHCO}_{3}, 1.24 \mathrm{~g} \mathrm{~L}^{-1}$; $\mathrm{MnCl}_{2}\left(\mathrm{H}_{2} \mathrm{O}\right)_{4}, 0.55 \mathrm{~g} \mathrm{~L}^{-1} ; \mathrm{MgSO}_{4} .7 \mathrm{H}_{2} 0,0.1 \mathrm{~g} \mathrm{~L}^{-1} ; \mathrm{CaCl}_{2}$, $0.02 \mathrm{~g} \mathrm{~L}^{-1}$; yeast extract, $1.5-5 \mathrm{~g} \mathrm{~L}^{-1}$, cysteine, $0.5 \mathrm{~g} \mathrm{~L}^{-1}$. The minimal medium was used as basis for further supplementation in this research. Additional products used for medium optimization were reinforced clostridial medium (RCM) (Oxoid, Hampshire UK), yeast extract, methanol, anaerobic vitamin and trace mix (Balch et al. 1979; Pacaud et al. 1985; Greening and Leedle 1989). The initial $\mathrm{pH}$ of all media was around 6.8-7.2. Biomass entrapment was done using zeolites Zeowater (2.5-5 nm) (Zeocem, Bystré Slovak republic). Resazurin was added as a redox indicator in all experiments. All media were autoclaved at $121{ }^{\circ} \mathrm{C}$ for $15 \mathrm{~min}$. Subsequent manipulations were done in the anaerobic chamber with a headspace composition $\mathrm{H}_{2} / \mathrm{CO}_{2} / \mathrm{N}_{2}$ of $10 / 10 / 80$ (v/v/v) (Airliquide, Belgium). The fermentation volume was $25 \mathrm{~mL}$ and incubations were done using $100 \mathrm{~mL}$ vessels, sealed with rubber stoppers. Cultures were incubated at $37{ }^{\circ} \mathrm{C}$ and were exposed to the atmosphere of the anaerobic chamber via a sterile needle and filter. At given time points, samples were collected using syringes. Inocula were preserved at $4{ }^{\circ} \mathrm{C}$ as freeze-dried pellets (LyoBeta Mini, Telstar) of $10 \mathrm{~mL}$ of $24 \mathrm{~h}$ grown cultures in BHI medium. Culture experiments with growing E. limosum were performed by inoculation of $100 \mu \mathrm{L}$ of $24 \mathrm{~h}$ revived culture in $25 \mathrm{~mL}$ of fresh medium and IX or spent hop-IX ( $5 \mathrm{~g} \mathrm{IX} \mathrm{L}^{-1}$ ) was added concomitantly. Resting cell suspensions (concentrated non-growing metabolically active cells, cNGMA) were obtained by centrifugation of stationary phase biomass (non-growing metabolically active cells, NGMA) for $10 \mathrm{~min}$ at $4500 \mathrm{~g}$ (C5810, Eppendorf, Hamburg Germany). Conversion was expressed as molar relative conversion of IX (fraction at the start versus at the end of the experiment), specific conversion was calculated using the molar relative conversion of IX per unit of biomass, the IX concentration in the extract and the spiked volume of extract. Basic metabolism was monitored by short chain fatty acid (SCFA) production. SCFA were extracted from the samples with diethyl ether and determined with a Di200 gas chromatograph (GC-FID) (Shimadzu,s-Hertogenbosch The Netherlands) (Nollet et al. 1997). Bacterial growth was analysed as an increase in optical density at $600 \mathrm{~nm}$. Analysis was done with use of spectrophotometer DR 3900 (Hach Lange, Belgium). Dilutions were made in physiological water $(0.85 \% \mathrm{NaCl})$ in case the OD exceeded 0.4. The biomass cell wet weight content was measured as the weight of the biomass pellet after samples were centrifuged at $12,500 \mathrm{~g}$ for $10 \mathrm{~min}$. Cell Dry Weight (CDW) was measured after the water content was evaporated at $105^{\circ} \mathrm{C}$ for $24 \mathrm{~h}$.

\section{Analysis}

Extractions and analysis of $\mathrm{X}, \mathrm{IX}$ and 8-PN were based on the work of Possemiers et al. 2005 and Bolca et al. 2007 (Possemiers et al. 2005; Bolca et al. 2007). Quantification was done by HPLC (Hitachi Chromaster, VWR Leuven, Belgium) equipped with a Photodiode Array Detector (Hitachi Chromaster 5430). A C18 reversed-phase column (Kinetex, $250 \times 4.6 \mathrm{~mm}, 5 \mu \mathrm{m}$ ) was used in combination with a gradient composed of solvent A (water acidified with $0.025 \%(\mathrm{v} / \mathrm{v})$ formic acid) and solvent $B$ (methanol acidified with $0.025 \%(\mathrm{v} / \mathrm{v})$ formic acid). The gradient was: $0-12.8 \mathrm{~min}$ : $45 \% \mathrm{~B}$ in $\mathrm{A} ; 12.8-17.9 \mathrm{~min}$ : 95\% B in A and 17.9-21.8: 45\% B in A. The flow-rate was

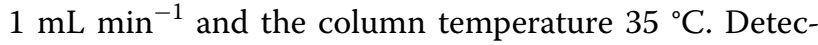
tion was done simultaneously at $295 \mathrm{~nm}$ (for IX, 8-PN) and at $370 \mathrm{~nm}$ (for X) using diode array detection. Peaks were identified by comparison of the retention times with those of authentic isolated reference compounds (Possemiers 2007), as well as by inspection of the respective UV spectra. External 4-point calibration curves were established for the compounds X, IX, 8-PN together, in a solution of $5 \mathrm{~g} \mathrm{~L}^{-1}$ in methanol $\left(\mathrm{R}^{2}>0.99\right)$. Concentrations were calculated based on peak area integration. For solid samples, X, (IX, 8-PN) were extracted with methanol (Nikolic and Van Breemen 2012). The samples were sonicated (Bandelin Sonorex) for 1 hour and kept in the fridge $\left(4{ }^{\circ} \mathrm{C}\right)$ for $3 \mathrm{~h}$. The upper phase after centrifugation for $15 \mathrm{~min}$ at $1300 \mathrm{~g}$ was analysed. For fermentation samples, $1 \mathrm{~mL}$ was mixed with $1 \mathrm{~mL}$ sodium acetate buffer $\left(0.1 \mathrm{~mol} \mathrm{~L}^{-1}, \mathrm{pH} 5\right)$ before extraction. The diluted samples were subsequently extracted twice with $5 \mathrm{~mL}$ diethyl ether. The solvent was evaporated at room temperature under a $\mathrm{N}_{2}$ stream and the residue was dissolved in methanol, transferred into HPLC vials and stored at 
$-20{ }^{\circ} \mathrm{C}$ prior to analysis. As an internal standard $5 \mathrm{~g} \mathrm{~L}^{-1}$ 4-hydroxybenzophenone in methanol was used.

\section{Results}

Xanthohumol content in hop and spent hop samples The xanthohumol (X) content differed considerably depending on the hop variety (Table 1 ) and this was presumed to be also the case for other residual compounds (not quantified). The IX content of the precipitates obtained after spent hops pretreatment was in the range of $5-10 \mathrm{~m} \%$ on wet weight.

\section{IX conversion in food and feed grade bioconversion medium}

The rich brain heart infusion (BHI) medium was used to deliver the proof of concept for conversion of pure IX at $25 \mathrm{mg} \mathrm{IX} \mathrm{L}^{-1}$ by Eubacterium limosum (Possemiers 2007). Yet, the high cost and presence of material from animal origin made this medium inappropriate for industrial production or nutritional applications. Initial efforts to look for a suitable alternative medium focused on the design and stepwise supplementation of a minimal medium, using different 5-day static incubations (Table 2). Vitamin and trace metal mix for anaerobes and/or yeast extract were added to account for sufficient enzyme and cofactor production (Balch et al. 1979; Greening and Leedle 1989). The Wood-Ljungdahl substrate methanol (up to $2 \% \mathrm{v} / \mathrm{v}$ ) was added for increased

Table 1 Quantification of xanthohumol in diverse hop and spent hop samples, as determined by HPLC-DAD

\begin{tabular}{ll}
\hline Hop variety & $\begin{array}{c}\text { Xanthohumol } \\
(\mathbf{X})(\mathbf{m} \%)^{\mathbf{a}}\end{array}$ \\
\hline Herkules & \\
Hop pellets & $1.00 \pm 0.01$ \\
Spent hop pellets & $1.45 \pm 0.01$ \\
Golding & \\
$\quad$ Hop pellets & $0.22 \pm 0.01$ \\
Spent hop pellets & $0.36 \pm 0.03$ \\
Blind sample & \\
$\quad$ Hop pellets & $1.22 \pm 0.10$ \\
Spent hop pellets & $1.39 \pm 0.07$ \\
Herkules & \\
$\quad$ Spent hop pellets & $1.22 \pm 0.07$ \\
Hallertauer exp. variety & \\
Spent hop pellets & $2.14 \pm 0.03$ \\
Hallertauer magnum & \\
Spent hop pellets & $0.64 \pm 00$ \\
Summit & \\
Hop pellets & $1.08 \pm 0.03$ \\
\hline
\end{tabular}

a Concentrations are expressed as mass percentage on the samples as such (without consideration of dry weights)
Table 2 Effect of different types of medium on growth and conversion of pure IX at $25 \mathrm{mg} \mathrm{IX} \mathrm{L}^{-1}$ by Eubacterium limosum

\begin{tabular}{|c|c|c|}
\hline $\begin{array}{l}\text { Condition }\left(10 \mathrm{H}_{2} / 10\right. \\
\left.\mathrm{CO}_{2} / 80 \mathrm{~N}_{2}(\mathrm{v} / \mathrm{v} / \mathrm{v})\right)\end{array}$ & Growth $\left(O D_{600}\right)$ & $\begin{array}{l}\text { Molar relative IX } \\
\text { conversion (HPLC- } \\
\text { DAD) }\end{array}$ \\
\hline BHI (reference) & ++ & ++ \\
\hline $\mathrm{MM}$ & + & - \\
\hline $\mathrm{MM} \pm$ additions & + & - \\
\hline MM, omission of glucose & - & - \\
\hline MM $2 \mathrm{~g} \mathrm{~L}^{-1}$ glucose & - & - \\
\hline MM $10 \mathrm{~g} \mathrm{~L}^{-1}$ glucose & + & - \\
\hline $\mathrm{BHI}+$ zeolite $(5 \% \mathrm{w} / \mathrm{v})$ & ++ & ++ \\
\hline $\mathrm{MM}+$ zeolite $(5 \% \mathrm{w} / \mathrm{v})$ & ++ & + \\
\hline $\mathrm{RCM}$ & ++ & ++ \\
\hline
\end{tabular}

Scoring was made relative to the incubation in $\mathrm{BHI}$ as positive control (' ++ ': $75-100 \%$ of positive control (reference); ${ }^{\prime}+': 50-75 \%$ of positive control; '-': $<50 \%$ or absence). $100 \%$ growth in the case of the reference corresponded with a 20 -fold increase in biomass (expressed as cell dry weight) compared to the inoculum

$B H I$ brain heart infusion medium, $M M$ minimal medium, $R C M$ reinforced clostridial medium

solubility of IX in combination with biomass entrapment with zeolites $(5 \% \mathrm{w} / \mathrm{v})$, and manganese was omitted specifically as it has been described to enhance the detrimental effects of hop ionophores (Behr and Vogel 2009, 2010). In order to observe possible (co-) metabolic interactions, glucose was omitted or decreased to the same amount as present in BHI medium $\left(2 \mathrm{~g} \mathrm{~L}^{-1}\right)$, ethanol was used as alternative for methanol to supply IX and the headspace composition was altered between $\mathrm{N}_{2}$ versus $\mathrm{H}_{2} / \mathrm{CO}_{2} / \mathrm{N}_{2}$ of $10 / 10 / 80(\mathrm{v} / \mathrm{v} / \mathrm{v})$. Using a minimal medium, efforts needed to maintain sufficient anaerobic conditions upon addition of IX were cumbersome and moderately reproducible (colour change of redox-indicator resazurin). Increasing the concentration of reducing agent may have led to accumulation of toxic oxidized intermediates as no improvements were obtained. Using a different approach, the commercially available complex medium reinforced clostridial medium (RCM), which can be produced in a food and feed grade fashion, was included in the study. Although some conditions using a minimal medium enabled growth, overall the results were not satisfying with regard to conversion (Table 2).

Trace elements for anaerobes could not increase conversion in minimal medium, suggesting that (micro-) nutrient requirements were not the major factor for low IX conversion in the minimal medium. Lowering the glucose levels in the minimal medium led to poor growth and metabolism. A combination of solvent addition for increased solubility with zeolite entrapment of the biomass initially led to increased biomass growth and short 
chain fatty acid production and was the only way for conversion in minimal medium in the same range as with BHI medium. Large aggregates of biomass were formed with the zeolites and butyrate and acetate production were 2-3 fold higher as compared to absence of zeolites. The latter production of basic metabolites resembled to values obtained for incubations in absence of IX source (data not included). The composition of RCM was finally selected as food and feed grade equivalent to BHI medium in terms of growth and conversion of $25 \mathrm{mg}$ IX $\mathrm{L}^{-1}$ to up to $30 \mathrm{mg} \mathrm{IX} \mathrm{L}^{-1}$. A controlled headspace (pressure and composition) was beneficial compared to a non-controlled confined headspace with regard to reproducible conversion. There was no difference between use of methanol (established methylated substrate for $E$. limosum) versus ethanol to supplement IX with regard to growth and conversion.

In search for the alternative production medium, rich substrate and/or biomass entrapment with zeolites were the most important factors.

\section{The bacteriostatic effects of isomerized spent hop extract}

Although a suitable production medium for pure IX conversion could be identified, any conversion of IX in isomerized spent hop extract (spent hop-IX) failed, confirming the traces of diverse hop compounds in spent hop extracts were antibacterial to E. limosum. A presumed technical feasible strategy to improve fermentation consisted of a supplemental spent hop pretreatment step, additionally removing the antibacterial residuals. As extra pretreatment of the spent hops, lab scale supercritical $\mathrm{CO}_{2}$ and hexane extraction were performed on different batches of (spent) hops, including differences in varieties, drying and storage conditions. Although there was no growth in any liquid incubation with spent hopIX, growth was observed after a lag phase upon subsequent transfers into fresh medium (1-5\% inoculation), whether or not supplemented with pure IX. The latter observation suggested very low minimum inhibitory concentrations (MIC) for spent hop compounds and/or a bacteriostatic yet not bactericidal effect of spent hops on E. limosum. Additional pretreatments and/or re-extractions on the side stream spent hops could not eliminate the inhibitory effects of the complex matrix of spent hop extract in the liquid incubations.

\section{Exploration of the non-growth phase: stationary phase conversion of IX}

The presence of diverse hop compounds in spent hop extract strongly impeded bacterial growth, until very low levels of around 1-5 mg IX L ${ }^{-1}$ medium. Therefore, the relation between IX conversion, growth and basic metabolism (acetate, butyrate production) was studied in more detail in growth and non-growth conditions (Figs. 2 and 3 ). In the growing cells experiment (i.e., IX was dosed at $30 \mathrm{mg}$ IX L ${ }^{-1}$ concomitant with inoculation of $0.5 \%$ of E. limosum), the culture started to grow immediately, and showed exponential growth till around $20 \mathrm{~h}$, reaching an optical density (OD) of about 0.8 (Fig. 2a). Short chain fatty acids (SCFA) butyrate and acetate, summed as chemical oxygen demand (COD), occurred during the exponential phase at a constant rate and slowed down upon reaching the stationary phase (Fig. 2b). The pH after $20 \mathrm{~h}$ was 6.1. The rate of SCFA production was elevated at the end, possibly due to cryptic growth and further lowered the $\mathrm{pH}$ to 5.6. IX was converted into 8-PN during the exponential phase, but no further conversion occurred upon prolonged incubation (Fig. 2c). IX conversion to 8-PN stopped at a relative molar conversion of around $65 \%$ and the stop coincided exactly with the onset of the stationary phase.

In the stationary phase experiment (i.e., IX was dosed at $30 \mathrm{mg} \mathrm{IX} \mathrm{L^{-1 }}$ when the culture had reached the stationary growth phase), arrest of growth was confirmed
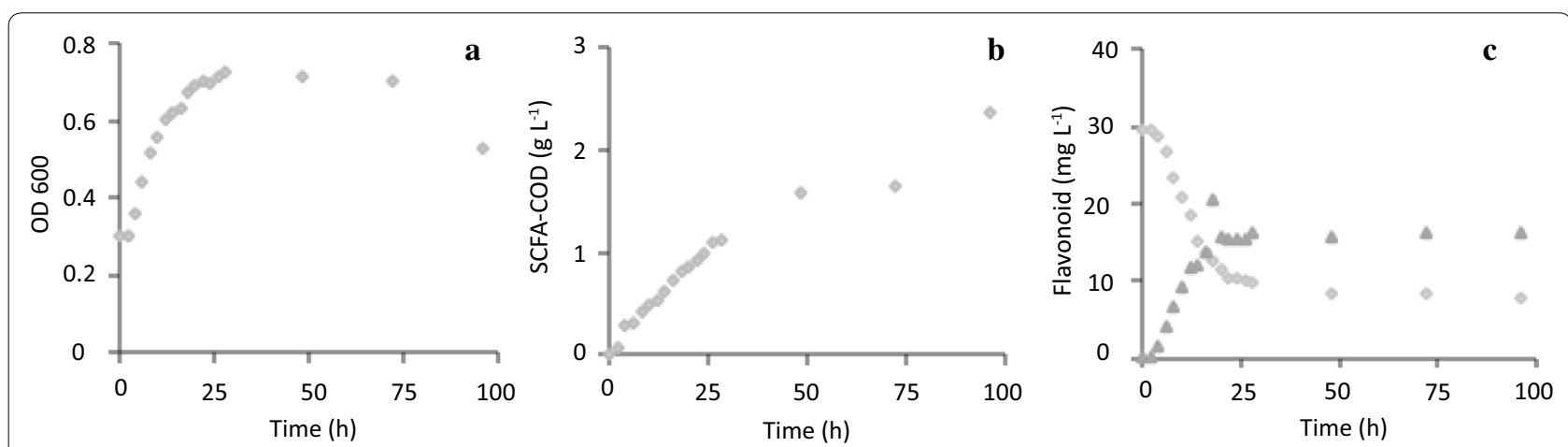

Fig. 2 Course of growth (a), basic metabolism, i.e., production of acetate and butyrate summed as chemical oxygen demand (COD) (b), and conversion of pure IX at $30 \mathrm{mg} \mathrm{IX} \mathrm{L-1} \mathrm{(rhombi:} \mathrm{IX;} \mathrm{triangles} \mathrm{8-PN)} \mathrm{(c)} \mathrm{during} \mathrm{growth} \mathrm{of} \mathrm{Eubacterium} \mathrm{limosum} \mathrm{in} \mathrm{reinforced} \mathrm{clostridial} \mathrm{medium} \mathrm{at} 37^{\circ} \mathrm{C}$ 

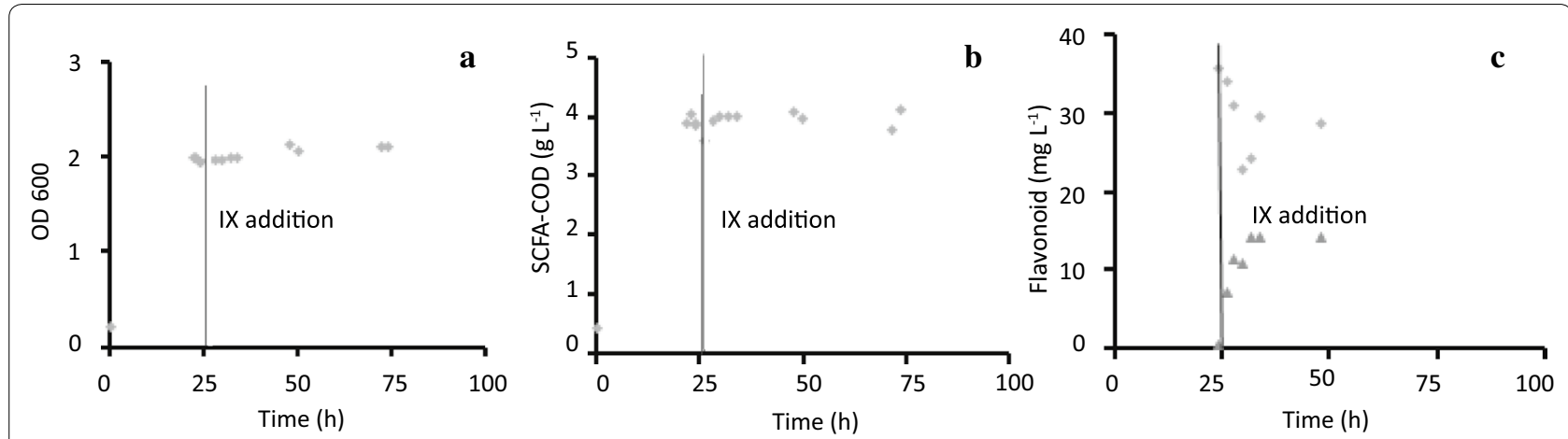

Fig. 3 Course of growth (a), basic metabolism, i.e., production of acetate and butyrate summed as chemical oxygen demand (COD) (b), and conversion of pure IX at $30 \mathrm{mg} \mathrm{IX} \mathrm{L}^{-1}$ (rhombi: IX; triangles 8-PN) (c) during stationary growth of Eubacterium limosum in reinforced clostridial medium at $37^{\circ} \mathrm{C}$

through successive OD determinations at close time points, indicating a stable and high OD value of 2 as compared to 0.8 when IX was dosed from the start (Fig. 3a). Stable SCFA concentrations were measured during the stationary phase and concentrations were more than double the amount as compared to incubations with IX present from the start in the growing cell experiment (Fig. 3b). The high SCFA accumulation resulted in a $\mathrm{pH}$ drop to $\mathrm{pH} 5$ after $20 \mathrm{~h}$ of incubation. Although the relative molar conversion only reached around $53 \%$, the initial conversion rate was much higher than for growing cells, yet, homogeneous sampling of 8-PN and IX was hampered in presence of the dense biomass (Fig. 3c). Cells which were able to convert IX into 8-PN in the stationary phase, represent non-growing metabolically active (NGMA) cells. There was almost no lag phase observed for conversion, the $\mathrm{CO}_{2}$ and $\mathrm{H}_{2}$ provided in the headspace of the incubation vessels may have already induced the WL enzymes during the growth phase.

Due to the altered consistency of the NGMA cells, the initial IX level appeared somewhat higher, yet the same volume of IX solution was spiked as for the growing experiment. Conversion values between 16 and $24 \mathrm{~h}$ were further confirmed in independent optimization experiments in time with coefficients of variation below $11 \%$ (data not shown).

Based on the growth experiment (Fig. 2), reasons for the cessation of IX conversion at the transition of the exponential phase to the stationary phase were initially thought to be: (I), conversion is growth-related and cannot occur during non-growth, (II), the $\mathrm{pH}$ has dropped too much in the batch incubation to allow further metabolism (pH 6.1), (III), toxicity of the end product has ceased conversion. The subsequent results of the stationary phase experiment (Fig. 3) demonstrated that: assumption (I) is not valid, i.e., IX conversion was not restricted to growth of the culture and yet presence of a lot of biomass was beneficial for rapid conversion and (II), $\mathrm{pH}$ effects may have occurred more rapidly because the $\mathrm{pH}$ at the moment of IX addition was already low $(\mathrm{pH}$ $5)$.

\section{Spent hop-IX conversion: sensitivity for $\mathrm{pH}$ and growth phase}

In order to further evaluate the effects of growth phase and $\mathrm{pH}$ on IX conversion, conversion of IX by growing and stationary phase cells was compared at increasing $\mathrm{pH}$ values. Above $\mathrm{pH}$ values of 7.5-7.7, lag phases of more than $10 \mathrm{~h}$ occurred for growing cells upon inoculation. Yet, higher $\mathrm{pH}$ values allowed to further increase the concentration of IX to $35 \mathrm{mg} \mathrm{L}^{-1}$ as a consequence of improved solubility.

When the $\mathrm{pH}$ of the stationary phase biomass (nongrowing metabolically active cells, NGMA cells) was kept at 7.5-7.7, fair and robust conversion of $35 \mathrm{mg}$ IX $\mathrm{L}^{-1}$ occurred, irrespective of IX source (pure IX versus 3 different batches of spent hop-IX) (Fig. 4). Conversion was $100 \%$ in case stationary phase biomass suspensions were used (i.e., concentrated stationary phase cells or cNGMA, obtained by centrifugation). Although high $\mathrm{pH}$ was beneficial for spent hop-IX conversion, the elevated $\mathrm{pH}$ on the other hand lead to impaired growth in growing cells experiments, lowering also pure IX conversion in this case.

\section{Discussion}

In this research, the aim was to develop a fermentation strategy for bacterial conversion of isoxanthohumol (IX) into the potent phytoestrogen 8-prenylnaringenin (8-PN), using antibacterial spent hops as source of IX. IX conversion is an $O$-demethylation reaction and was therefore suggested to be part of the Wood-Ljungdahl 

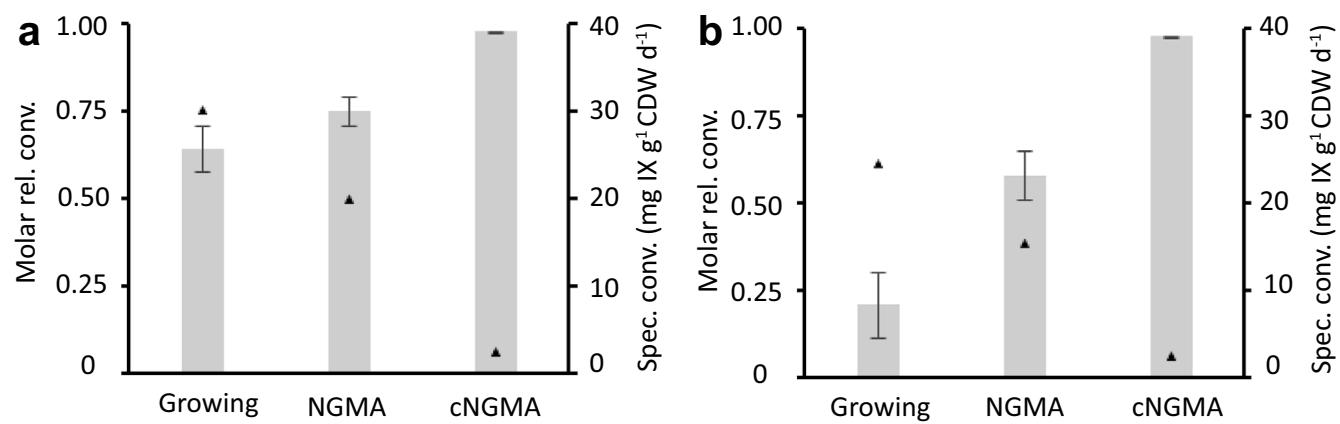

Fig. 4 Conversion of $35 \mathrm{mg} \mathrm{IX} \mathrm{L}^{-1}$ by Eubacterium limosum at the maximal $\mathrm{pH}$ for growth of 7.5-7.7 for $\mathrm{IX}(\mathrm{n}=3)(\mathbf{a})$ and three different sources of spent hop-IX (b). Bars indicate molar relative conversion, triangles indicate specific conversion for the growing biomass, non-growing metabolically active (NGMA) cells and $10 \times$ concentrated NGMA (cNGMA)

(WL) pathway of Eubacterium limosum (Genthner et al. 1981; Drake 1994; Liu and Suflita 1994). Different parameters such as growth phase, $\mathrm{pH}$, headspace and medium composition needed to be optimized in order to achieve maximal solubility and enzyme induction next to low redox and toxicity. A commercial complex rich medium, reinforced clostridial medium (RCM) and controlled headspace, were selected as most efficient with regard to medium requirements. Diauxic growth patterns were not observed, on the contrary, the demethylation of IX into 8-PN was enhanced in presence of glucose and seemed unaffected by use of the WL substrate methanol as solvent. Improved IX conversion in complex rich medium was mainly attributed to improved solubility of IX, $\mathrm{pH}$ stability, low and stable redox and protective effects of lipid materials and proteins. Stevens et al. previously demonstrated that carbohydrates considerably influenced the solubility of IX by forming soluble complexes (Stevens et al. 1999a). The (apparent) solubility of IX in either water, $5 \%$ ethanol, beer at $1 \% \mathrm{w} / \mathrm{w}$ carbohydrates and different brewing worths at 8.4 and $13 \% \mathrm{w} / \mathrm{w}$ of carbohydrates was respectively $5,6,27,40$ and $43 \mathrm{mg} \mathrm{IX} \mathrm{L}^{-1}$ at $23{ }^{\circ} \mathrm{C}$. Next to carbohydrate complexation reactions, IX also binds to proteins (Stevens et al. 1999a).

Although initially growth and conversion seemed related (IX conversion was only observed concomitant with considerable biomass formation), hourly sampling during growing and resting cell experiments revealed that stationary phase cells may well be used for IX conversion. The latter observation was of great interest, given the fact that the most interesting economic source of IX, spent hops, acted as a strong bacteriostatic agent. Following this line, spent hop-IX could indeed be converted using stationary phase biomass. Stable low redox and/or energy levels may have been more optimal in the densely grown culture, providing cellular resistance to ionophore and oxidative stresses.
Although growth was increasingly impaired at $\mathrm{pH}$ values above $\mathrm{pH} 7.5$, conversion with non-growing biomass was slightly further improved after increasing the $\mathrm{pH}$ during conversion to $7.8-8$ (results not shown). $\mathrm{pH}$ values may affect bacterial cultures via different ways, including altered membrane permeability, changes in cellular physiology and/or expression of transporters (Dilworth et al. 1999; Petrackova et al. 2010; Siliakus et al. 2017).

The enzymes of the WL pathway are not membrane bound (Hess et al. 2013) which requires effective transfer of the substrates into the cell via passive diffusion or transporters. The shift in $\mathrm{pH}$ to higher values may increase the dissociation of the protic weak acids (bitter acids, IX and 8-PN) and therefore affect the diffusion rates. In addition, also the aqueous solubility at room temperature of 8-PN almost triples for an increase in $\mathrm{pH}$ from neutral to $\mathrm{pH} 8$ (from 3 to $8 \mathrm{mg} \mathrm{L}^{-1}$ ) (Riis et al. 2007). The theoretic dissociated fraction of the weak acids was approached using the Henderson-Hasselbalch equation for a range of pKa values for bitter acids, IX and 8-PN (Verzele and De Keukeleire 1991; Simpson and Smith 1992; Hermans-Lokkerbol et al. 1997; Irwin and Shoichet 2005; Cattoor 2012; NCBI 2019; PhytoHub 2019a, 2019b; PubChem 2019) and indeed confirmed $\mathrm{pH} 7.8-8$ could be the most optimal value for fermentation (Fig. 5). For the bitter acids, the potential $\mathrm{pH}$ dependent differences in bioavailability may be most interesting, given their lower range of $\mathrm{pKa}$ values and yet fairly lipophilic (estimated) $\log \mathrm{P}$ values of around 3.9-6.2. At $\mathrm{pH}$ 8, the bioavailability via diffusion of a considerable fraction of bitter acids may be much decreased (the undissociated fraction is close to zero) whereas a large fraction of IX and 8-PN may remain available for diffusion into the cells.

Finally, the whole process would intuitively benefit from enzymatic conversion as compared to whole cells, 


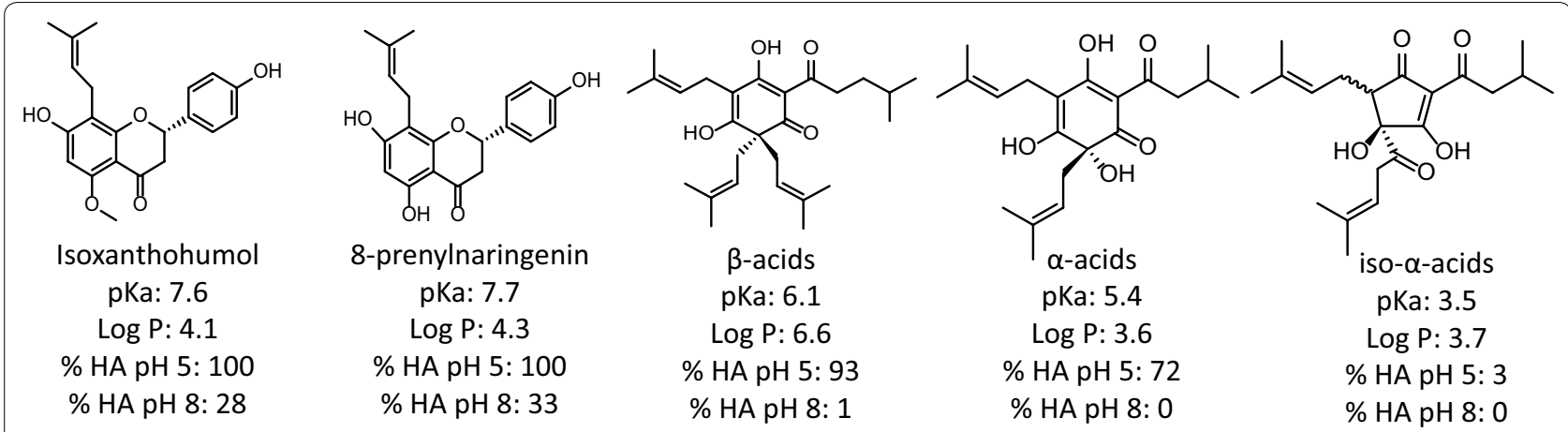

Fig. 5 Theoretic calculations of undissociated fractions (HA) of substrate IX, product 8-PN and traces of bitter acids in spent hops at pH 5 (pH of stationary phase cultures in absence of $\mathrm{pH}$ control) versus $\mathrm{pH} 8$ (maximal tolerable $\mathrm{pH}$ value for Eubacterium limosum), based on reported pKa values and the Henderson-Hasselbalch equation (Simpson and Smith 1992). Considering the relatively high (estimated) log P values of the most abundant antibacterial hop compounds, bioavailability via diffusion into the bacterial cells may be much altered based on the $\mathrm{pH}$ of the medium. $\% \mathrm{HA}$ : undissociated fraction of the weak acids. The structures in the figure are the most commonly represented stereo form of the compounds

overcoming energy spilling reactions by ionophores and solubility issues. Demethylation of IX into 8-PN seems a one-step reaction, yet, the key enzymes catalysing the methyl cleavage are the $O$-demethylases, consisting of a four-component cytosolic enzyme system (Studenik et al. 2012) (Fig. 1b). Specifically, methyltransferase I (MT I) binds the substrate, catalyses the cleavage of the $\mathrm{C}-\mathrm{O}$ bond and the transfer of the methyl group to a coppercorrinoid protein $\left(\left[\mathrm{CO}^{\mathrm{I}}\right]-\mathrm{CP}\right)$, yielding demethylated products and $\left[\mathrm{CH}_{3}-\mathrm{CO}^{\mathrm{III}}\right]-\mathrm{CP}$. Subsequently, methyltransferase II (MT II) mediates the transfer of the methyl group from $\left[\mathrm{CH}_{3}-\mathrm{CO}^{\mathrm{III}}\right]-\mathrm{CP}$ to tetrahydrofolate (FH4), producing methyl-FH4 and $\left[\mathrm{CO}^{\mathrm{I}}\right]-\mathrm{CP}$. The enzyme system requires low redox, which is mediated by activating enzymes $(\mathrm{AE})$. In order for the reactions to occur, the redox has to be below $-290 \mathrm{mV}$ versus the standard hydrogen electrode (SHE) at $\mathrm{pH} 7.5$ in presence of $\mathrm{AE}$ and ATP or below $-450 \mathrm{mV}$ in their absence (Studenik et al. 2012). The genes encoding MT-I, CP and MT-II are organized in one transcription unit as an operon, while the AE gene is located separately (Studenik et al. 2012). Chen and coworkers identified, cloned and expressed the 0 -demethylase system of intestinal Eubacterium limosum ZL-II in Escherichia coli (Chen et al. 2016). Enzymatic demethylation of test substrate secoisolariciresinol (SECO) was confirmed using a reconstruction of the complete $O$-demethylase reaction system in vitro but the reaction efficiency was weak (about $6 \%$ of SECO was converted after reacting for $8 \mathrm{~h}$ ). Since the $\mathrm{O}$-demethylase activity requires a cooperation of four different proteins, it may be challenging to reach high efficiency using in vitro. So far, the highest bio-conversion capacity of IX from economic sources into 8-PN was obtained in this research, using whole non-growing metabolically active cells of Eubacterium limosum. The boundaries for production set at lab scale from this study are being used for optimization to a scalable bioprocess.

\section{Abbreviations \\ 8-PN: 8-prenylnaringenin; X: Xanthohumol; IX: Isoxanthohumol; $\mathrm{SCO}_{2}$ : Super- critical $\mathrm{CO}_{2}$; MIC: Minimum inhibitory concentration; WL: Wood-Ljungdahl; NGMA: Non-growing metabolically active; CNGMA: Concentrated non-grow- ing metabolically active; $\mathrm{BHI}$ : Brain heart infusion; RCM: Reinforced clostridial medium; MM: Minimal medium.}

\section{Acknowledgements}

Dr. Thijs De Mulder is thanked for proofreading the manuscript. Dr. Arne Heyerick is thanked for sharing his experience on (spent) hop pretreatment, analysis and for providing hop materials.

\section{Authors' contributions}

All authors contributed to the study conception and design. Material preparation, data collection and analysis were performed by EM, SB and JLG. The manuscript was written by EM. All authors read and approved the final manuscript.

\section{Funding}

This work was financially supported by the Flemish Agency Flanders Innovation and Entrepreneurship (VLAIO Grant Number: 2016.0224).

\section{Availability of data and materials}

Data is available on request.

\section{Ethics approval and consent to participate}

Not applicable.

\section{Consent for publication}

Not applicable.

\section{Competing interests}

Willy Verstraete and Sam Possemiers are inventors of the UGent patent Enzymatic Demethylation of Flavonoids (WO2006099699). Tom Van de Wiele is professor at the involved UGent department. Esther Moens, Selin Bolca, Anita Van Landschoot and Jan L. Goeman have no conflict of interest.

\section{Author details}

${ }^{1}$ ProDigest BVBA, Technol Pk 82, 9052 Ghent, Belgium. ${ }^{2}$ Ugent, CMET, Coupure Links 653, 9000 Ghent, Belgium. ${ }^{3}$ Ugent, Dept Biotechnology, Valentin Vaerwyckweg 1, 9000 Ghent, Belgium. ${ }^{4}$ Ugent, Dept Organic 
and Macromolecular Chemistry, Krijgslaan 281-S4, 9000 Ghent, Belgium.

${ }^{5}$ AVECOM NV, Ind Weg 122P, 9032 Wondelgem, Belgium.

Received: 10 April 2020 Accepted: 17 April 2020

Published online: 24 April 2020

\section{Bibliography}

Aniol M, Zolnierczyk A (2008) Extraction of spent hops using organic solvents. J Am Soc Brew Chem 66:208-214. https://doi.org/10.1094/ASBCJ -2008-0818-01

Anioł M, Huszcza E, Bartmańska A, Żołnierczyk A, Mączka W, Wawrzeńczyk C (2007) Trace analysis of hop essential oils in spent hop. J Am Soc Brew Chem 65:214-218. https://doi.org/10.1094/ASBCJ-2007-0820-01

Balch WE, Fox GE, Magrum L, Woese CR, Wolfe RS (1979) Methanogens: reevaluation of a unique biological group. Microbiol Rev 43:260-296

Bartmańska A, Wałecka-Zacharska E, Tronina T, Popłoński J, Sordon S, Brzezowska E, Bania J, Huszcza E (2018) Antimicrobial properties of spent hops extracts, flavonoids isolated therefrom, and their derivatives. Molecules 23:2059-2068. https://doi.org/10.3390/molecules23082059

Behr J, Vogel RF (2009) Mechanisms of hop inhibition: hop ionophores. J Agric Food Chem 57:6074-6081. https://doi.org/10.1021/jf900847y

Behr J, Vogel RF (2010) Mechanisms of hop inhibition include the transmembrane redox reaction. Appl Environ Microbiol 76:142-149. https://doi. org/10.1128/AEM.01693-09

Bocquet L, Sahpaz S, Bonneau N, Beaufay C, Mahieux S, Samaillie J, Roumy $\checkmark$, Jacquin J, Bordage S, Hennebelle T, Chai F, Quetin-Leclercq J, Neut C, Rivière C (2019) Phenolic compounds from Humulus lupulus as natural antimicrobial products: new weapons in the fight against methicillin resistant Staphylococcus aureus, Leishmania mexicana and Trypanosoma brucei strains. Molecules 24:1024. https://doi.org/10.3390/molecules2 4061024

Bolca S, Possemiers S, Herregat A, Huybrechts I, Heyerick A, De Vriese S, Verbruggen M, Depypere H, De Keukeleire D, Bracke M, De Henauw S, Verstraete W, Van de Wiele T (2007) Microbial and dietary factors are associated with the equol producer phenotype in healthy postmenopausal women. J Nutr 137:2242-2246. https://doi.org/10.1093/jn/137.10.2242

Cattoor K (2012) Bioavailability of hop-derived bitter acids: key factors for the health-beneficial properties of beer. Dissertation, Ghent University

Cermak P, Olsovska J, Mikyska A, Dusek M, Kadleckova Z, Vanicek J, Nyc O, Sigler K, Bostikova V, Bostik P (2017) Strong antimicrobial activity of xanthohumol and other derivatives from hops (Humulus lupulus L.) on gut anaerobic bacteria. APMIS 125:1033-1038. https://doi.org/10.1111/ apm.12747

Chen J, Deng C, Zhang Y, Liu Z, Wang P, Liu S, Qian W, Yang D (2016) Cloning, expression, and characterization of a four-component O-demethylase from human intestinal bacterium Eubacterium limosum ZL-II. Appl Microbiol Biotechnol 100:9111-9124. https://doi.org/10.1007/s0025 3-016-7626-1

Cocaign M, Wilberg E, Lindley ND (1991) Sequential demethoxylation reactions during methylotrophic growth of methoxylated aromatic substrates with Eubacterium limosum. Arch Microbiol 155:496-499. https://doi. org/10.1007/BF00244968

Dilworth M, Glenn A, Konings W, Booth I, Poole R, Krulwich T, Rowbury R, Stock J, Slonczewski J, Cook G, Padan E, Kobayashi H, Bennett G, Matin A, Skulachev V (1999) Problems of adverse $\mathrm{pH}$ and bacterial strategies to combat it. Bact Responce pH 221:4-18

Drake HL (1994) Acetogenesis, acetogenic bacteria, and the Acetyl-CoA "Wood/Ljungdahl" pathway: past and current perspectives. Acetogenesis. Springer, US, pp 3-60

Fernandez JL, Simpson WJ (1993) Aspects of the resistance of lactic acid bacteria to hop bitter acids. J Appl Bacteriol 75:315-319. https://doi. org/10.1111/j.1365-2672.1993.tb02782.x

Genthner BR, Davis CL, Bryant MP (1981) Features of rumen and sewage sludge strains of Eubacterium limosum, a methanol- and $\mathrm{H}_{2}-\mathrm{CO}_{2}$-utilizing species. Appl Environ Microbiol 42:12-19

Greening RC, Leedle JAZ (1989) Enrichment and isolation of Acetitomaculum ruminis, gen. nov., sp. nov.: acetogenic bacteria from the bovine rumen. Arch Microbiol 151:399-406. https://doi.org/10.1007/BF00416597
Hermans-Lokkerbol ACJ, Hoek AC, Verpoorte R (1997) Preparative separation of bitter acids from hop extracts by centrifugal partition chromatography. J Chromatogr A 771:71-79. https://doi.org/10.1016/S0021-9673(97)00123 $-4$

Hess V, Schuchmann K, Müller V (2013) The ferredoxin:nAD + oxidoreductase (Rnf) from the acetogen Acetobacterium woodii requires $\mathrm{Na}+$ and is reversibly coupled to the membrane potential. J Biol Chem 288:3149631502. https://doi.org/10.1074/jbc.M113.510255

Irwin JJ, Shoichet BK (2005) ZINC-a free database of commercially available compounds for virtual screening. J Chem Inf Model 45:177-182. https:// doi.org/10.1021/ci049714+

Jeong J, Bertsch J, Hess V, Choi S, Choi I, Chang I, Müller V (2015) Energy conservation model based on genomic and experimental analyses of a carbon monoxide-utilizing, butyrate-forming acetogen, Eubacterium limosum KIST612. Appl Environ Microbiol 81:4782-4790. https://doi. org/10.1128/AEM.00675-15

Kamiński DM, Gawęda K, Arczewska M, Senczyna B, Gagoś M (2017) A kinetic study of xanthohumol cyclization to isoxanthohumol — a role of water. J Mol Struct 1139:10-16. https://doi.org/10.1016/j.molstruc.2017.03.027

Kim HJ, Yim SH, Han F, Kang BY, Choi HJ, Jung DW, Williams DR, Gustafson KR, Kennelly EJ, Lee IS (2019) Biotransformed metabolites of the hop prenylflavanone isoxanthohumol. Molecules. https://doi.org/10.3390/ molecules24030394

Krishna G, Czerkawski J, Breckenridge G (1986) Fermentation of various preparations of spent hops (Humulus /upulus L.) using the rumen simulation technique (Rusitec). Agric Wastes 17:99-117. https://doi. org/10.1016/0141-4607(86)90049-1

Lebloas P, Loubiere P, Lindley ND (1994) Use of unicarbon substrate mixtures to modify carbon flux improves vitamin B12 production with the acetogenic methylotroph Eubacterium limosum. Biotechnol Lett 16:129-132. https://doi.org/10.1007/BF01021658

Lebloas P, Lindley ND, Loubiere P (1996) Regulation of carbon and energy metabolism during the linear growth phase in batch fermentations of the acetogenic methylotroph Eubacterium limosum on methanol/CO2. Enzyme Microb Technol 19:187-195. https://doi.org/10.1016/01410229(95)00230-8

Leclerc M, Bernalier A, Donadille G, Lelait M (1997) $\mathrm{H}_{2} / \mathrm{CO}_{2}$ metabolism in acetogenic bacteria isolated from the human colon. Anaerobe 3:307-315. https://doi.org/10.1006/anae.1997.0117

Lindley ND, Loubiere P, Pacaud S, Mariotto C, Goma G (1987) Novel products of the acidogenic fermentation of methanol during growth of Eubacterium limosum in the presence of high concentrations of organic acids. Microbiology 133:3557-3563. https://doi.org/10.1099/00221287-133-12-3557

Liu S, Suflita JM (1994) Anaerobic biodegradation of methyl esters by Acetobacterium woodii and Eubacterium limosum. J Ind Microbiol 13:321-327. https://doi.org/10.1007/BF01569735

Loubiere P, Lindley ND (1991) The use of acetate as an additional co-substrate improves methylotrophic growth of the acetogenic anaerobe Eubacterium limosum when $\mathrm{CO}_{2}$ fixation is rate-limiting. J Gen Microbiol 137:2247-2251. https://doi.org/10.1099/00221287-137-9-2247

Loubiere P, Gros E, Paquet V, Lindley ND (1992) Kinetics and physiological implications of the growth behaviour of Eubacterium limosum on glucose/methanol mixtures. J Gen Microbiol 138:979-985. https://doi. org/10.1099/00221287-138-5-979

Martinez SE, Davies NM (2015) Enantiospecific pharmacokinetics of isoxanthohumol and its metabolite 8-prenylnaringenin in the rat. Mol Nutr Food Res 59:1674-1689. https://doi.org/10.1002/mnfr.201500118

Milligan SR, Kalita JC, Heyerick A, Rong H, De Cooman L, De Keukeleire D (1999) Identification of a potent phytoestrogen in hops (Humulus lupulus L.) and beer. J Clin Endocrinol Metab 84:2249-2249. https://doi. org/10.1210/jcem.84.6.5887

Moriya H, Tanaka S, lida Y, Kitagawa S, Ichi AS, Taga A, Terashima H, Yamamoto A, Kodama S (2018) Chiral separation of isoxanthohumol and 8-prenylnaringenin in beer, hop pellets and hops by HPLC with chiral columns. Biomed Chromatogr. https://doi.org/10.1002/bmc.4289

Müller V (2003) Energy conservation in acetogenic bacteria. Appl Environ Microbiol 69:6345-6353. https://doi.org/10.1128/ aem.69.11.6345-6353.2003

NCBI (2019) 8-Prenylnaringenin. https://pubchem.ncbi.nlm.nih.gov/compo und/480764\#section=Computed-Properties. Accessed 30 Sep 2019 
Nikolic D, Van Breemen RB (2012) Analytical methods for quantitation of prenylated flavonoids from hops. Curr Anal Chem 9:71-85. https://doi. org/10.2174/157341113804486554

Nikolic D, Li Y, Chadwick LR, Pauli GF, van Breemen RB (2005) Metabolism of xanthohumol and isoxanthohumol, prenylated flavonoids from hops (Humulus lupulus L.), by human liver microsomes. J Mass Spectrom 40:289-299. https://doi.org/10.1002/jms.753

Nollet L, Vande Velde I, Verstraete W (1997) Effect of the addition of Peptostreptococcus productus ATCC35244 on the gastro-intestinal microbiota and its activity, as simulated in an in vitro simulator of the human gastro-intestinal tract. Appl Microbiol Biotechnol 48:99-104. https://doi. org/10.1007/s002530051022

Pacaud S, Loubiere P, Goma G (1985) Methanol metabolism by Eubacterium limosum B2: effects of $\mathrm{pH}$ and carbon dioxide on growth and organic acid production. Curr Microbiol 12:245-250. https://doi.org/10.1007/ BF01567972

Pacaud S, Loubiere P, Goma G, Lindley ND (1986) Effects of various organic acid supplements on growth rates of Eubacterium limosum B2 on methanol. Appl Microbiol Biotechnol 24:75-78. https://doi.org/10.1007/ BF00266289

Petrackova D, Vecer J, Svobodova J, Herman P (2010) Long-term adaptation of Bacillus subtilis 168 to extreme $\mathrm{pH}$ affects chemical and physical properties of the cellular membrane. J Membr Biol 233:73-83. https://doi. org/10.1007/s00232-010-9226-9

PhytoHub (2019a) 8-prenylnaringenin. http://phytohub.eu/entries/PHUBO 00373. Accessed 3 Jan 2018

PhytoHub (2019b) Isoxanthohumol. http://phytohub.eu/entries/PHUB000384 . Accessed 3 Jan 2018

Possemiers S (2007) Activation of proestrogens from hops by human intestinal bacteria: conversion of isoxanthohumol into the potent phytoestrogen 8-prenylnaringenin. Dissertation, Ghent University

Possemiers S, Heyerick A, Robbens V, De Keukeleire D, Verstraete W (2005) Activation of proestrogens from hops (Humulus lupulus L.) by intestinal microbiota; conversion of isoxanthohumol into 8-prenylnaringenin. J Agric Food Chem 53:6281-6288. https://doi.org/10.1021/jf0509714

PubChem (2019) Isoxanthohumol. In: Natl. Cent. Biotechnol. Inf. https://pubch em.ncbi.nlm.nih.gov/compound/513197\#section=MeSH-Entry-Terms. Accessed 30 Sep 2019

Riis T, Bauer-Brandl A, Wagner T, Kranz H (2007) pH-independent drug release of an extremely poorly soluble weakly acidic drug from multiparticulate extended release formulations. Eur J Pharm Biopharm 65:78-84. https:// doi.org/10.1016/j.ejpb.2006.07.001

Rój E, Tadić VM, Mišić D, Žižović I, Arsić I, Dobrzyńska-Inger A, Kostrzewa D (2015) Supercritical carbon dioxide hops extracts with antimicrobial properties. Open Chem 13:13-24. https://doi.org/10.1515/ chem-2015-0131

Rong H, Zhao Y, Lazou K, De Keukeleire D, Milligan SR, Sandra P (2000) Quantitation of 8-prenylnaringenin, a novel phytoestrogen in hops (Humulus lupulus L.), hop products, and beers, by benchtop HPLC-MS using electrospray ionization. Chromatographia 51:545-552. https://doi. org/10.1007/BF02490811

Sakamoto K, Konings WN (2003) Beer spoilage bacteria and hop resistance. Int J Food Microbiol 89:105-124
Sakamoto K, Margolles A, van Veen HW, Konings WN (2001) Hop resistance in the beer spoilage bacterium Lactobacillus brevis is mediated by the ATPbinding cassette multidrug transporter HorA. J Bacteriol 183:5371-5375

Schick D, Schwack W (2018) Detection of estrogen active compounds in hops by planar yeast estrogen screen. J Chromatogr A 1532:191-197. https:// doi.org/10.1016/j.chroma.2017.11.069

Siliakus MF, van der Oost J, Kengen SWM (2017) Adaptations of archaeal and bacterial membranes to variations in temperature, $\mathrm{pH}$ and pressure. Extremophiles 21:651-670. https://doi.org/10.1007/s00792-017-0939-x

Simpson WJ, Smith ARW (1992) Factors affecting antibacterial activity of hop compounds and their derivatives. J Appl Bacteriol 72:327-334. https:// doi.org/10.1111/j.1365-2672.1992.tb01843.x

Stevens JF, Taylor AW, Clawson JE, Deinzer ML (1999a) Fate of xanthohumol and related prenylflavonoids from hops to beer. J Agric Food Chem 47:2421-2428. https://doi.org/10.1021/JF990101K

Stevens JF, Taylor AW, Deinzer ML (1999b) Quantitative analysis of xanthohumol and related prenylflavonoids in hops and beer by liquid chromatography-tandem mass spectrometry. J Chromatogr A 832:97-107. https:// doi.org/10.1016/S0021-9673(98)01001-2

Studenik S, Vogel M, Diekert G (2012) Characterization of an O-demethylase of Desulfitobacterium hafniense DCB-2. J Bacteriol 194:3317-3326. https:// doi.org/10.1128/JB.00146-12

Suzuki K, Sami M, Kadokura H, Nakajima H, Kitamoto K (2002) Biochemical characterization of horA-independent hop resistance mechanism in Lactobacillus brevis. Int J Food Microbiol 76:223-230

Suzuki K, lijima K, Sakamoto K, Sami M, Yamashita H (2006) A review of hop resistance in beer spoilage lactic acid bacteria. J Inst Brew 112:173-191. https://doi.org/10.1002/j.2050-0416.2006.tb00247.x

van Breemen RB, Yuan Y, Banuvar S, Shulman LP, Qiu X, Alvarenga RFR, Chen S-N, Dietz BM, Bolton JL, Pauli GF, Krause E, Viana M, Nikolic D (2014) Pharmacokinetics of prenylated hop phenols in women following oral administration of a standardized extract of hops. Mol Nutr Food Res 58:1962-1969. https://doi.org/10.1002/mnfr.201400245

Van Opstaele F, Goiris K, De Rouck G, Aerts G, De Cooman L (2012) Production of novel varietal hop aromas by supercritical fluid extraction of hop pellets-part 1: preparation of single variety total hop essential oils and polar hop essences. J Supercrit Fluids 69:45-56. https://doi.org/10.1016/J. SUPFLU.2012.05.009

Verzele M, De Keukeleire D (1991) Chemistry and analysis of hop and beer bitter acids, vol 27. Elsevier Science, Amsterdam

Wilhelm H, Wessjohann LA (2006) An efficient synthesis of the phytoestrogen 8-prenylnaringenin from xanthohumol by a novel demethylation process. Tetrahedron 62:6961-6966. https://doi.org/10.1016/j.tet.2006.04.060

Yin H, Dong J, Yu J, Li Y, Deng Y (2018) A novel horA genetic mediated RCA detection of beer spoilage lactobacillus. Microb Pathog 114:311-314. https://doi.org/10.1016/j.micpath.2017.11.064

\section{Publisher's Note}

Springer Nature remains neutral with regard to jurisdictional claims in published maps and institutional affiliations.

\section{Submit your manuscript to a SpringerOpen ${ }^{\circ}$ journal and benefit from:}

- Convenient online submission

- Rigorous peer review

- Open access: articles freely available online

- High visibility within the field

Retaining the copyright to your article

Submit your next manuscript at springeropen.com 